Brit. J. industr. Med., 1956, 13, 192.

\title{
A QUANTITATIVE TECHNIQUE FOR STUDYING THE EFFECT OF DUST ON PHAGOCYTIC CELLS IN VITRO
}

\author{
BY \\ J. MARKS and M. ANN MASON \\ From the Central Tuberculosis Laboratory and the Pneumoconiosis Research Unit, Cardiff
}

(RECEIVED FOR PUBLICATION NOVEMBER 13, 1955)

Tissue culture techniques have so far contributed little to pneumoconiosis research, possibly because they have not permitted a quantitative assessment of toxicity. The method now presented attempts to remedy this deficiency. A single sample of tridymite, which in vivo is one of the most fibrogenic forms of silica, was used in all the experiments described below. An investigation into the effect of other types of dust using the same methods will be reported elsewhere.

\section{The Technique in Outline}

Exudates were induced in guinea-pigs by injecting $12 \mathrm{ml}$. of liquid paraffin intraperitoneally under ether anaesthesia. After 48 or, more usually, 72 hours the guinea-pig was killed by a blow on the neck and the peritoneal cavity washed out with Tyrode's solution. The cell suspension was freed from liquid paraffin by means of a separating funnel and a total and differential cell count made. The suspension was then centrifuged lightly, the supernatant fluid discarded, and the deposit re-suspended in tissue culture medium. The medium consisted of Tyrode's solution, sufficient guinea-pig and horse serum to give $12.5 \%$ of each after all additions, and streptomycin at a final concentration of $5 \mu \mathrm{g}$. per $\mathrm{ml}$. Dust was introduced into cultures by adding a standard volume of a suspension in Ringer's solution to individual chambers. The volume used was $0.06 \mathrm{ml}$. delivered as 3 drops from a calibrated dropping pipette, care being taken to keep the dust evenly suspended during the operation. The chambers were cylindrical bottles incubated on their sides on an exactly horizontal surface. Rolling was prevented by stacking them in a box standing on its side. Cultures were incubated for three days at $37^{\circ} \mathrm{C}$. and were not disturbed during this period for inspection or any other purpose. Each consisted of $2 \times 10^{6}$ cells in $1 \mathrm{ml}$. of medium. About 30 chambers were accommodated in a sealed 3-litre jar at the bottom of which $25 \mathrm{ml}$. of $1 \%$ sodium chloride was placed. An atmosphere of air plus $5 \% \mathrm{CO}_{2}$ was used and, to permit gaseous interchange, the liners were removed from the screw-caps of the bottles and the caps left loose. Since macrophages in tissue culture change their appearance on cooling, they were examined without delay after removal from the incubator. Rotation of the bottles to bring the lower surface of the chamber uppermost allowed microscopical examination of the cells adhering to the glass with a $2 / 3$ in. objective. Removal of the medium was not necessary. Some minutes were available before the cells showed signs of suffering from their exposure.

Details of the technique outlined above are given in the following sections together with experimental evidence in favour of certain of the procedures recommended.

Details of Technique

Culture Chamber.- The success of the method depends on the use of a chamber with a concave inferior surface on to which cells and dust gravitate. Such an arrangement appears greatly to favour an even distribution of the dust and cells and uniform phagocytosis throughout the culture. In our earlier experiments they were allowed to settle on to a plane surface but a regular distribution could not then be ensured. The bottle used as the culture chamber was cylindrical, approximately $50 \mathrm{~mm}$. long and $20 \mathrm{~mm}$. in diameter, with a capacity of $14.5 \mathrm{ml}$. It was made of thin neutral glass and fitted with a metal screw cap.*

New bottles and their caps were boiled in sodium oleate solution, rinsed, boiled twice in tap water, and finally once in distilled water. The cap liners were discarded. Cleansing after use was similar except for an extra preliminary boiling in oleate solution followed by vigorous brushing. Chambers were sterilized in the autoclave with their lids loose and dried off at $37^{\circ} \mathrm{C}$. When they had been used about six times, the bottles were treated with acid dichromate for three days after their usual cleansing. They were subsequently washed meticulously, soaked in several changes of tap water over a period of some days, and finally left overnight in distilled water before being returned to use.

The Cell Population.-In the great majority of exudates,

*This bottle, designated the Sanders neutral vial, is obtainable from Messrs. S. H. Travis \& Co. We are indebted to Dr. F. K. Sanders for bringing it to our notice. 
between 70 and $90 \%$ of the cells were mononuclear and the remainder polymorphonuclear. If the proportion of polymorphs exceeded $40 \%$ cultures were likely to be unsatisfactory. An excessive proportion of polymorphs was obtained when an attempt was made to use light liquid paraffin which is easier to inject than the ordinary kind. The mononuclear cells consisted of macrophages, often containing liquid paraffin, cells resembling blood monocytes, and small cells with scanty cytoplasm whose nature was uncertain. Polymorphs rapidly disappeared from cultures but the fate of the different types of mononuclear cell could not be distinguished. With knowledge on this point standardization of the cell inoculum might have been improved but in the event only the total cell count was standardized.

In the given experimental conditions, cell cultures were healthy only within certain limits of population density, corresponding approximately to inocula of between $0.5 \times 10^{6}$ and $4 \times 10^{6}$ cells per chamber in $1 \mathrm{ml}$. of medium. The effect of different amounts of tridymite dust on cell populations of different size is shown in Table 1. The inoculum of $0.25 \times 10^{6}$ cells was suboptimal, controls without dust being less healthy than

TABLE 1

EFFECT OF TRIDYMITE DUST ON EXUDATE CELL CULTURES OF DIFFERENT POPULATION SIZE

\begin{tabular}{|c|c|c|c|c|c|}
\hline \multirow{2}{*}{$\begin{array}{c}\text { Amount of } \\
\text { Dust per } \\
\text { Chamber } \\
(\mu \mathrm{g} .)\end{array}$} & \multicolumn{5}{|c|}{$\begin{array}{l}\text { Toxic Effect* with Given Inoculum of } \\
\text { Cells per Chamber }\end{array}$} \\
\hline & $4 \times 10^{6}$ & $2 \times 10^{8}$ & $1 \times 10^{6}$ & $0.5 \times 10^{6}$ & $0.25 \times 10^{6}$ \\
\hline $\begin{array}{l}30 \\
15 \\
7 \cdot 5 \\
3 \cdot 75\end{array}$ & $\begin{array}{c}+ \\
\text { Trace } \\
\mathbf{0} \\
\mathbf{0}\end{array}$ & $\begin{array}{c}++ \\
+ \\
\text { Trace } \\
0\end{array}$ & $\begin{array}{c}+++ \\
++ \\
+ \\
0\end{array}$ & $\begin{array}{c}+++ \\
+++ \\
++ \\
\text { Trace }\end{array}$ & $\begin{array}{l}+++ \\
+++ \\
+++ \\
+++\end{array}$ \\
\hline
\end{tabular}

* See text for explanation of symbols. controls with larger inocula. The results show a close correlation between the degree of cell damage observed and the amount of dust available per cell. It was to be expected therefore that the effect of a given amount of dust would vary somewhat in different experiments according to the proportion of viable cells in the inoculum. The extent of the variation is shown in Table 2 which records titrations of the standard tridymite suspension in 20 experiments, each with a different cell donor. The same end-point was obtained in 13 titrations and a difference of one dilution in the remainder. When comparisons are to be made between the results of different experiments it appears advisable to include such a standard dust titration in each as a reference and as a check on experimental conditions.

Reading.-The normal undusted culture after three days' incubation contained very few cells which were not translucent and amoeboid in shape. The degree of elongation of the cells and their processes varied considerably with different cell donors and could not be used to estimate a toxic effect. However, loss of amoeboid shape accompanied by an increase in optical density and a decrease in the number of cells adherent to the glass was reliable evidence of cell damage. A very small proportion of the cells (considerably less than $0.1 \%$ ) appeared not to phagocytose dust and to be unharmed in high concentrations of a toxic dust. Such resistant cells had the appearance of fibroblasts in tissue culture but may have been desquamated lining cells. They did not interfere with assessments of dust toxicity and no investigation was made into their nature or origin.

In undusted cultures the cells adherent to the glass were distributed in a characteristic manner. They were found over the entire floor of the chamber but were somewhat more numerous over the middle third of its length.

TABLE 2

EFFECT OF ONE SA MPLE OF TRIDYMITE IN 20 EXPERIMENTS EACH WITH DIFFERENT CELL DONOR

\begin{tabular}{|c|c|c|c|c|c|c|c|c|c|c|}
\hline \multirow{2}{*}{$\begin{array}{c}\text { Amount of Dust } \\
\text { per Chamber } \\
(\mu \mathrm{g} .)\end{array}$} & \multicolumn{10}{|c|}{ Toxic Effect in Each of 20 Experiments } \\
\hline & 1 & 2 & 3 & 4 & 5 & 6 & 7 & 8 & 9 & 10 \\
\hline 60 & +++ & $++t$ & • & - & +++ & +++ & +++ & $+t+$ & +++ & +++ \\
\hline 30 & ++ & ++ \pm & ++ & +++ & ++ & +++ & +++ & ++ & ++ & $+t+$ \\
\hline 15 & + & + \pm & + & ++ & Trace & ++ & + \pm & + & + \pm & ++ \\
\hline $7 \cdot 5$ & Trace & $\overline{\text { Trace }}$ & Trace & + & 0 & Trace & + & 0 & + & + \\
\hline $3 \cdot 75$ & 0 & 0 & 0 & Trace & $\mathbf{0}$ & $\mathbf{0}$ & Trace & $\mathbf{0}$ & Trace & $\mathbf{0}$ \\
\hline
\end{tabular}

\begin{tabular}{|c|c|c|c|c|c|c|c|c|c|c|}
\hline \multirow{2}{*}{$\begin{array}{c}\text { Amount of Dust } \\
\text { per Chamber } \\
(\mu \mathrm{g} .)\end{array}$} & \multicolumn{10}{|c|}{ Toxic Effect in Each of 20 Experiments } \\
\hline & 11 & 12 & 13 & 14 & 15 & 16 & 17 & 18 & 19 & 20 \\
\hline 60 & +++ & - & $+t+$ & $+t+$ & +++ & +++ & - & +++ & ++ \pm & ++ \pm \\
\hline 30 & $++t$ & \pm \pm & \pm+ & ++ \pm & $+t \pm$ & ++ & ++ & +++ & ++ & ++ \\
\hline 15 & ++ & + & Trace & ++ & ++ & \pm \pm & \pm \pm & ++ & + \pm & \pm \pm \\
\hline $7 \cdot 5$ & Trace & Trace & 0 & + & + & + & + & \pm \pm & Trace & Trace \\
\hline $3 \cdot 75$ & 0 & 0 & 0 & Trace & Trace & Trace & Trace & + & 0 & 0 \\
\hline
\end{tabular}

The end-point in dust titrations (shown by heavy line) was determined by a degree of cell damage exceeding $+($ see text). A standard inoculum of $2 \times 10^{\circ}$ exudate cells per chamber was used throughout. 


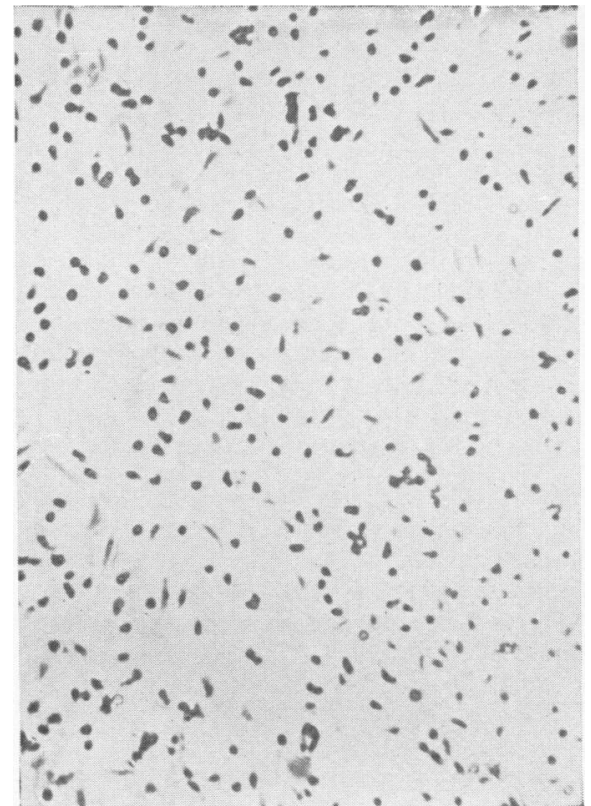

FIG. 1.- Normal exudate cell culture after three days' incubation, stained with haematoxylin and photographed through culture bottle. $\times 120$

Transversely their distribution was fairly uniform over several millimetres. Where densest they were close to one another but not in contact.

It was found convenient to define the following three main degrees of cell damage :-

\section{$+\quad$ Considerably fewer cells adhere to the glass than in the controls. They are optically denser and less active than normal cells, a large proportion having partially or completely rounded off. \\ $++\quad$ Less than $10 \%$ of the cells remain on the glass. Most of the survivors are optically dense whether rounded off or not. \\ +++ Fewer than 50 cells remain. These may show signs of damage or be fibroblast-like cells apparently indif- ferent to dust.}

It was often useful to recognize intermediate degrees of damage which were designated " trace", + \pm and ++ \pm .

To facilitate the comparison of different dusts or the effect of different conditions on the toxicity of a single dust, the method was adopted of determining the smallest amount of dust necessary to produce an arbitrary degree of cell damage, namely, damage greater than that designated + .

The appearance of an undusted three-day leucocyte culture is shown in Fig. 1. The effect of incubating a replicate culture with $15 \mu \mathrm{g}$. of tridymite X2612 is shown in Fig. 2. The degree of damage in the dusted culture was recorded as ++ . Dusted cells are usually slightly larger than normal cells and in addition, owing to their greater optical density, their size is somewhat emphasized by photography.

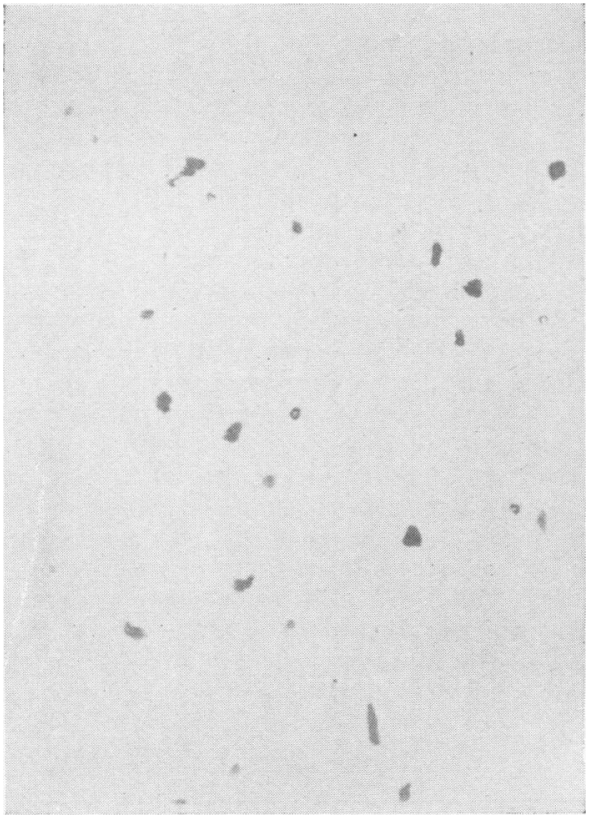

Fig. 2.-Cell culture replicate of that in Fig. 1 but incubated with $15 \mu \mathrm{g}$. of tridymite dust X2612. $\times 120$.

Medium and Atmosphere.-Sterile Tyrode's solution was prepared aseptically from $25 \%$ glucose, $5 \%$ sodium bicarbonate, and a solution of the remaining constituents. These three solutions were autoclaved separately, the bicarbonate in sealed ampoules after saturating with $\mathrm{CO}_{2}$. Cultures fared much better in medium containing homologous serum as compared with horse serum. However, equal parts of each proved satisfactory. (The horse serum was supplied filtered and unheated by the Serum Research Institute, Carshalton.) Final serum concentrations of $17 \%, 25 \%$, and $40 \%$ were compared. The results with the two higher concentrations were similar and slightly superior to those with the lowest. Comparisons were made of sera from different donors and of sera stored at $4^{\circ} \mathrm{C}$. for periods varying from two to 90 days. Neither variable appeared to influence the health of cultures.

The $p \mathrm{H}$ of serum-Tyrode solution was higher than the optimum for macrophages. A sufficiently large cell inoculum produced enough acid to make the $p \mathrm{H}$ favourable but not when dust reduced its vitality. This difficulty was avoided by adding $\mathrm{CO}_{2}$ to the atmosphere. Concentrations of $2.5 \%$ and $5 \% \mathrm{CO}_{2}$ were equally satisfactory; $10 \%$ was slightly excessive. The choice was finally made of an atmosphere of $5 \% \mathrm{CO}_{2}$ in air.

Length of Incubation.-With the technique described above, full activity of the macrophage cultures was attained after two days' incubation and deterioration became apparent after five days, the medium not having been renewed. When the tridymite suspension was 
titrated during different periods of incubation. the arbitrary end-point changed from $30 \mu \mathrm{g}$. per $\mathrm{ml}$. of culture after the first and second days to $15 \mu \mathrm{g}$. after the third and fourth and to $7.5 \mu \mathrm{g}$. after the fifth. The period of three days' incubation was chosen for standard practice as being long enough for the display of dust toxicity without risk of exhaustion of the medium.

Dust.-The sample of tridymite X2612 used in the present investigation had a specific surface of $2 \cdot 2 \mathrm{m.} . \mathrm{g}$. and a size distribution as follows:-

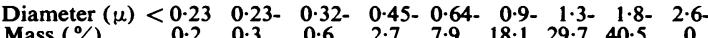

A stock suspension was made by suspending $40 \mathrm{mg}$. of the dust in $10 \mathrm{ml}$. of Ringer's solution and sterilized by heating in a boiling water-bath for 15 minutes. Its toxicity did not appear to change during three months' storage at $4^{\circ} \mathrm{C}$. Dispersion of the dust was assisted by shaking mechanically before use.

\section{Discussion}

The chief applications of an experimental technique for studying the effect of dust would appear to be in estimating the hazards of exposure to different dusts, in examining protective agents, and in investigating the mechanism of dust toxicity. Animals have been used in such investigations with a certain degree of success but suffer from the disadvantage that observation over long periods of time is necessary. Studies on the mechanism of dust toxicity are difficult in the intact animal because the chief effects observed are not the primary damage to the phagocytic cells but the secondary vascular and connective tissue reactions. The technique described in the present work is perhaps more complex than that required for experiments on animals but gives results quickly and economically and permits direct observation of the effect of dust on the cells ingesting it. In a later communication it will be shown that in most respects its results are comparable with those obtained in intact animals.

\section{Summary}

A technique is described in which phagocytes and dust are allowed to settle together on to the concave floor of a tissue culture chamber which is reversed for direct microscopical observation after a few days' incubation. The toxicity of a dust may be titrated by determining the concentration necessary to produce a standard degree of cell damage.

We are indebted to Dr. G. Nagelschmidt, Safety in Mines Research Establishment, Sheffield, for the sample of tridymite X2612 and to Mr. C. A. Lediard for the photographs. 